\title{
Unemployment Dynamics and Age
}

\author{
Gerard J. van den Berg * \\ A. Gijsbert C. van Lomwel ${ }^{\dagger}$ \\ Jan C. van Ours $\stackrel{\ddagger}{\ddagger}$
}

September 8, 1998

\begin{abstract}
Youth unemployment is an issue of primary concern in Western European countries. In this paper we analyze dynamics in unemployment for youths, adults (prime-aged individuals), and elderly. We use quarterly French unemployment data, stratified by gender, age group, and duration, over the period 1982-1994. We find that the inflow rate of male youths is more sensitive to the business cycle than the inflow rate of adults, but that the outflow of adults is more sensitive than the outflow of youths. Seasonal effects affect youth unemployment mainly by fluctuations in the inflow. The results are used for a policy recommendation.
\end{abstract}

*Dept. of Economics, Free University Amsterdam, De Boelelaan 1105, NL-1081 HV Amsterdam, The Netherlands, Tinbergen Institute, and CEPR.

${ }^{\dagger}$ Dept. of Economics, Tilburg University, P.O. Box 90153, NL-5000 LE Tilburg, The Netherlands, and CentER for Economic Research.

$\ddagger$ Dept. of Economics, Tilburg University, P.O. Box 90153, NL-5000 LE Tilburg, The Netherlands, CentER for Economic Research, and CEPR.

Keywords: unemployment duration, business cycle, duration dependence, seasonality.

JEL code: J6.

The Département de Marché du Travail of the Ministère du Travail, de l'Emploi et de la Formation Professionelle of France kindly provided the data. Thanks to Jaap Abbring and Bas van der Klaauw for helpful discussions. 


\section{Introduction}

There is hardly any study on youth unemployment that does not start by stating that governments are deeply concerned by high rates of youth unemployment. In France, the country we focus on in this paper, youth unemployment rates are double digit and much larger than those of adults. Moreover, French unemployment rates are higher than the OECD average. In 1994, the unemployment rate in France was 9.7 (13.1) percent for men (women) aged 25-54, and 24.2 (31.6) percent for men (women) aged 15-24 (OECD (1996)).

There are several economic explanations for the relatively great concern for youth unemployment compared to unemployment in general. First, an early spell of unemployment may increase the incidence and duration of future unemployment, because youths are not yet firmly rooted into the labour market and may be stigmatized by an early spell of unemployment. Second, this early spell of unemployment hampers the accumulation of human capital. Not only will human capital not increase due to the absence of on-the-job training, the human capital acquired at school is depreciated as well. Finally, commitment to society as a whole may reduce, the devil finding work for idle hands (OECD (1984a)).

This concern has led the French government to enact special youth programs and policies. In 1981 the "Future for youth plan" (Plan avenir jeunes) was brought into effect. The main objective of this plan was to stimulate the employment of young people by various economic premiums and exemptions for employers and by various training and workfare programs. The number of participants to such programs increased substantially after the 1986 "Emergency plan for youth employment" (Plan d'urgence pour l'emploi des jeunes), which introduced stronger incentives to participate and facilitated the development of new programs (see OECD (1984b), CSERC (1996) and Bonnal, Fougère and Sérandon (1997) for details on various programs and the numbers of individuals enrolled in them).

In this paper we study unemployment dynamics among different age groups in a systematic way, focusing on business-cycle and calendar-time effects on the inflow and outflow rates of unemployment. These in turn determine the movement of the unemployment rate over time. Most of the previous studies on labour market dynamics have taken a micro approach (see Devine and Kiefer (1991) for an overview). This approach focuses on personal characteristics that affect individual re-employment probabilities. Macroeconomic conditions are at most included as an additional regressor (see for example Dynarski and Sheffrin (1990)). Recently, Sider (1985), Baker (1992), and Butler and MacDonald (1986), amongst others, have stressed the effect of the business cycle on aggregate flows of individuals over a long period of time, using aggregate data. A few empirical studies on unemploy- 
ment dynamics focus on the youth labour market. Clark and Summers (1982), by examining US data from the Current Population Survey of 1976, find that the high rate of joblessness among youths is a problem of job availability. Their data convey a picture of a dynamic labour market, where youth employment is very responsive to aggregate demand. The participation rate shows a large increase in the summer months, mainly due to summer-only workers. Lynch (1985) examines duration data for a sample of London youths taken from a longitudinal survey of young workers in the greater London area who left school at age 16 in the summer of 1979. The determinants of re-employment probabilities are estimated using a Weibull proportional hazard model. The main conclusion concerns the evidence of negative duration dependence. Lynch (1989) uses a US data set of young workers (both male and female) in the National Longitudinal Survey to estimate the determinants of re-employment probabilities. She finds strong negative duration dependence, and differences between men and women. Moreover she finds that local demand conditions play an important role. Chapter VI of the OECD 1983 Employment Outlook (OECD (1983)) also explores differences between youth and adult unemployment. Youths face a much higher risk of becoming unemployed, and most of the separations are involuntary. Moreover, youths have a higher propensity to terminate spells of unemployment by way of withdrawing from the labour force. The teenage labour force flows, in particular in North America, show a strong seasonal pattern. Finally, Chapter IV of the OECD 1996 Employment Outlook (OECD (1996)) examines the youth labour market over the 1980s and 1990s. Youth employment and unemployment seems to be exceptionally sensitive to the overall state of the labour market. From all these empirical studies we derive the following stylized facts on youth unemployment. First, youth unemployment is much more responsive to aggregate economic conditions than adult unemployment. Secondly, youth unemployment has a strong seasonal component. Thirdly, youth unemployment is heterogeneous with respect to gender.

In the present paper we examine whether these results are confirmed in a formal econometric analysis. For example, we examine to what extent youths are disproportionally affected by a recession. We estimate a model in which the business cycle affects the inflow and outflow into and out of unemployment. Concerning the latter we adopt a model in which the individual exit probability is duration dependent and also depends on the business cycle and on individualspecific characteristics. It is important to allow for the latter type of characteristics when dealing with cyclical effects on the exit rate out of unemployment. The weeding out of the individuals with the highest individual-specific effects occurs faster in the top of the cycle than in a recession (see Van den Berg and Van Ours (1996)). As a result, individual heterogeneity causes the duration dependence of 
the aggregate exit probability to be less negative in a recession than in the top of the cycle. If one does not take this into account then the business cycle effect in the recession will be over-estimated; that is, the estimated effect on the individual exit probability will be less severe than the real effect. In our analysis, we estimate different models for different age groups and genders, and we allow for heterogeneity of unobserved individual characteristics. In sum, the estimates provide an econometrically more careful description of the business cycle effects than can be obtained from simply eyeballing the graphs of raw data. Note that previous studies on unemployment durations typically assume that duration dependence is invariant across age groups (some studies, however, restrict attention to data from just one age group, see e.g. the articles by Lynch mentioned above). In the empirical analysis we use French administrative data which distinguish unemployment by elapsed duration and by gender. The data are quarterly and cover the period 1982.IV-1994.IV. Our model and estimation method are based on Abbring, Van den Berg and Van Ours (1994).

The plan of the paper is as follows. In Section 2 we present the model and the empirical implementation. Section 3 describes the data. In Section 4, the estimation results are presented, and we decompose unemployment variation into the contributions of its determinants, notably business cycle effects. From a policy point of view, it is important to know differences across age groups of the instantaneous effect of the business cycle on inflow and outflow. For example, if exit probabilities of youths respond to business cycles at a later stage than the exit probabilities of adults, then this may help policy makers to anticipate cycles of youth unemployment. The results can also be used to predict, for a given state of the business cycle, which types of employed and unemployed workers suffer most from the cycle in terms of their chances on the labour market. In Section 5 we therefore discuss the policy implications of our results in some detail.

\section{The model and the empirical implementation}

In this section we describe the model for the exit probabilities out of unemployment. Since this model is described in detail in Abbring, Van den Berg and Van Ours (1994), the present exposition is brief. In the first subsection we start with a sketch of the type of data we use, and we discuss the role of measurement er-

rors. The second subsection deals with the unemployment duration model. The parameterization of the model is discussed in the third subsection. 


\subsection{Observation of unemployment}

We use two measures of time, each with a different origin. The variable $t$ denotes the duration of a spell of unemployment for a given individual. The variable $\tau$ denotes calendar time. We take $t$ and $\tau$ to have the same measurement scale, apart from the difference in origin. Both $t$ and $\tau$ are discrete variables. For example, consider an individual who is unemployed for $t$ periods at calendar time $\tau$. If he fails to leave unemployment in period $t$, he will be unemployed for $t+1$ periods at calendar time $\tau+1$.

Aggregate data give the total numbers of individuals in the labour market who are unemployed for $t$ periods of time $(t=0,1,2, \ldots)$ at calendar times $\tau(\tau=$ $\left.\tau_{0}, \tau_{0}+1, \tau_{0}+2, \ldots\right)$. By comparing the number of individuals who are unemployed for $t$ periods of time at $\tau$ to the number unemployed for $t+1$ periods at $\tau+1$, we observe the fraction of the former who leave unemployment at $t$. This fraction of course equals the exit probability out of unemployment $\theta(t \mid \tau)$ of an individual who is unemployed for $t$ periods, when calendar time equals $\tau$ at the moment of potential exit:

$$
\theta(t \mid \tau)=\frac{U(t \mid \tau)-U(t+1 \mid \tau+1)}{U(t \mid \tau)}
$$

In reality we do not exactly observe the numbers $U(t \mid \tau)$, due to e.g. roundingoff errors and administrative errors. In addition, the unemployment definition changes over time. We capture this by way of stochastic errors. From now on, a tilde denotes an observed variable whereas the absence of a tilde denotes the true value of the corresponding model variable. We assume that

$$
\widetilde{U}(t \mid \tau)=U(t \mid \tau) \epsilon_{t, \tau}
$$

with

$$
\log \epsilon_{t, \tau} \sim N\left(0, \sigma^{2}\right)
$$

In the empirical analysis we allow for non-zero correlations between errors $\epsilon_{t, \tau}$ at one single calendar moment. Thus, we specify the correlation between $\log \epsilon_{t^{*}, \tau^{*}}$ and $\log \epsilon_{t^{* *}, \tau^{* *}}$ to be equal to $r^{\left|t^{*}-t^{* *}\right|}$ if $\tau^{*}=\tau^{* *}$, and 0 otherwise. Combining the equations (1) and (2), we obtain

$$
\log (1-\tilde{\theta}(t \mid \tau))=\log (1-\theta(t \mid \tau))+e_{t, \tau}
$$

where

$$
e_{t, \tau}:=\log \epsilon_{t+1, \tau+1}-\log \epsilon_{t, \tau}
$$

Equation (3) links the data to the true exit probabilities. In the next subsection we present a model for $\theta(t \mid \tau)$. 


\subsection{The model}

The model expresses the true exit probabilities in terms of the (determinants of the) exit probabilities at the individual level. The relation is established by way of aggregating over individual unemployment duration distributions.

It is assumed that all variation in the individual exit probabilities out of unemployment can be explained by the prevailing unemployment duration $t$ and calendar time $\tau$, and by observed and unobserved heterogeneity across individuals. The effect of $t$ represents genuine duration dependence, i.e. dependence of individual exit probabilities on the elapsed unemployment duration. Calendar time is assumed to capture macro effects (including business cycle and seasonal effects) on individual exit probabilities, as well as structural changes influencing these probabilities. In the data we use, we have two observed individual characteristics that can be used as an explanatory variable $x$, namely the gender and age group (youth, adult, elderly). We estimate the model separately for both gender types and the three age groups, and in the sequel we suppress the conditioning on the prevailing value of $x$.

We denote the probability that an individual leaves unemployment right after $t$ periods of unemployment, given that he is unemployed for $t$ periods at calendar time $\tau$, and conditional on his unobserved characteristics $v$, by $\theta(t \mid \tau, v)$. By definition, this is the exit probability out of unemployment (or hazard) at $\tau$ conditional on $t$ and $v$. We assume proportionality of individual exit probabilities $\theta(t \mid \tau, v)$ : there are functions $\psi_{1}$ and $\psi_{2}$ such that

$$
\theta(t \mid \tau, v)=\psi_{1}(t) \cdot \psi_{2}(\tau) \cdot v
$$

with $\psi_{1}$ and $\psi_{2}$ positive and uniformly bounded from above. The functions $\psi_{1}$ and

$\psi_{2}$ represent the duration dependence and the calendar time dependence of the individual exit probabilities out of unemployment. Furthermore, the distribution of $v$ is such that, for every $t$ and $\tau$, $\operatorname{Pr}(0<\theta(t \mid \tau, v)<1)=1$.

We now turn to the effect of calendar time at the inflow into unemployment on the exit probabilities. We assume this to act by way of the composition of the inflow. This is modelled by a calendar time dependent scale parameter of the distribution function $G_{\tau}$ of $v$,

$$
G_{\tau}\left(\psi_{3}(\tau) v\right)=G(v)
$$

with $G(v)$ the distribution of the composition of the inflow at the calendar time base $\tau=0$, and $\psi_{3}$ positive and uniformly bounded from above. If $\psi_{3}(\tau)>1$ 
then the individuals entering unemployment at $\tau$ on average have lower values of their unobserved characteristics (i.e. lower exit probabilities) than the individuals entering at the calendar time base. For instance, this parameter could capture the effect of (relatively) highly qualified graduates, usually entering the labour market in the third quarter. To express the exit probabilities $\theta(t \mid \tau)$ appearing in the r.h.s. of equation (3) in terms of $\theta(t \mid \tau, v)$, we have to integrate $v$ out of the latter. It can be shown that the following relation holds (see Abbring, Van den Berg and Van Ours (1994)),

$$
\theta(t \mid \tau)=\psi_{1}(t) \psi_{2}(\tau) \psi_{3}(\tau-t) \frac{E_{v}\left[v \prod_{i=1}^{t}\left(1-\psi_{1}(t-i) \psi_{2}(\tau-i) \psi_{3}(\tau-t) v\right)\right]}{E_{v}\left[\prod_{i=1}^{t}\left(1-\psi_{1}(t-i) \psi_{2}(t-i) \psi_{3}(\tau-t) v\right)\right]}(5)
$$

in which $E_{v}($.$) denotes the expectation with respect to the distribution G$. Substitution of equation (5) in equation (3) establishes the link between the observed exit probabilities and the model determinants.

Our model is closed by the specification of an equation for the inflow size (the incidence equation). We measure the size of the inflow by the number of people in the first duration class $U(0 \mid \tau)$. This number is smaller than the true inflow, because people who enter and leave within a quarter are excluded. ${ }^{1}$ We specify

$$
U(0 \mid \tau)=\psi_{4}(\tau)
$$

with the function $\psi_{4}$ positive and uniformly bounded from above. Substitution of (6) into equation (2) links the observed $\widetilde{U}(0 \mid \tau)$ and the unknown function $\psi_{4}(\tau)$.

In the model described above, the structural determinants are the functions $\psi_{1}, \psi_{2}, \psi_{3}, \psi_{4}$ and $G$. As shown by Van den Berg and Van Ours (1996), the assumptions above ensure nonparametric identifiability of the model without effects of calendar time at the moment of inflow. In particular, they ensure that duration dependence and unobserved heterogeneity can be distinguished empirically without the need to specify parametric functional forms on the shape of $\psi_{1}$ or $G$. From equation (5) it is clear that the functions $\psi_{1}(t)$ and $\psi_{2}(\tau)$ are identified from the multiplicative effect on $\theta(t \mid \tau)$ of respectively $t$ and $\tau$. By expanding the product terms in equation (5) it follows that $\theta(t \mid \tau)$ depends on $G(v)$ by way of the first $t+1$ moments of $v$, denoted by $\mu_{i}$, and that these are identified from interaction effects between $t$ and $\tau$ (i.e., between $\psi_{1}(t)$ and $\left.\psi_{2}(\tau)\right)$ in $\widetilde{\theta}(t \mid \tau)$. If the calendar time effect on $\psi_{3}$ is repetitive, as in case of seasonal effects, then $\psi_{3}$ is identified, see Abbring, Van den Berg and Van Ours (1994). In the sequel, we assume that

\footnotetext{
${ }^{1}$ In the literature both this measure and the true inflow have been used (e.g. Layard, Nickell and Jackman (1991)). From additional analysis it is clear that the dynamic features of both series are similar.
} 
$\psi_{3}$ only includes seasonal effects. The function $\psi_{4}$ is trivially identified from the $\widetilde{U}(0 \mid \tau)$ data.

\subsection{Parameterization}

We adopt the nonparametric estimation method by Abbring, Van den Berg and Van Ours (1994). First,

$$
\psi_{1}(t)=\exp \left\{\sum_{i=0}^{n_{t}-1} \psi_{1 i} I_{1, i}(t)\right\}
$$

in which $I_{i, t}=1$ if $t=i$ and 0 otherwise, and $n_{t}$ is the number of duration classes considered. The unobserved heterogeneity distribution is estimated through the "parameters" representing its normalized moments $\mu_{1}, \gamma_{2}, \gamma_{3}, \ldots, \gamma_{n_{t}}$;

$$
\gamma_{i}:=\frac{\mu_{i}}{\mu_{1}^{i}}
$$

We adopt products of flexible high-order polynomials (capturing business cycle effects) and dummy variables (capturing seasonal effects) for the structural functions $\psi_{2}$ and $\psi_{4}$. In notation to be explained below,

$$
\psi_{j}(\tau)=\omega_{j}(\tau) \psi_{j, c}(\tau), \quad j=2,4
$$

whereas $\psi_{3}(\tau)$ is specified to equal $\omega_{3}(\tau)$. The seasonal effects in $\psi_{2}, \psi_{3}$ and $\psi_{4}$ are specified as

$$
\omega_{j}(\tau)=\exp \left\{\sum_{s=1}^{4} \omega_{s j} I_{s}(\tau)\right\}
$$

where $I_{s}$ is an indicator function for season $s, s=1, \ldots, S$. The cyclical and trend effects in $\psi_{2}$ and $\psi_{4}$ are represented by polynomials of indexed order that are mutually orthogonal on the data interval for $\tau$. Let the functions $p_{1}(\tau), p_{2}(\tau), p_{3}(\tau), \ldots$ denote these Chebyshev polynomials. Then

$$
\psi_{j, c}(\tau)=\sum_{i=0}^{k} \alpha_{i j} p_{i}(\tau), \quad j=2,4
$$

Note that we can compare our estimates to the way in which conventional business cycle indicators behave over time. We normalize the duration model by taking $\alpha_{02}=\alpha_{03}=1, \omega_{21}=\omega_{31}=0$ (so the first season is the base season), and $\psi_{1}(0)=1\left(\right.$ so $\left.\psi_{10}=0\right)$. We normalize the incidence model by taking $\alpha_{04}=1$ 
and $\omega_{41}=0$. Finally, we include a multiplicative term $\exp (c)$ in $\psi_{4}$, where $c$ is a parameter to be estimated.

Before finishing this section we point out a procedure to test the MPH assumption (see Van den Berg and Van Ours (1996)). Consider the estimates of $\gamma_{2}, . ., \gamma_{n_{t}}$. If the model is correct, then $\gamma_{2}, . ., \gamma_{n_{t}}$ are mutually consistent as normalized moments of a distribution with positive bounded support (from zero until the upper bound depending on the functions $\psi_{1}$ and $\psi_{2}$ ). This can be tested for.

For example, if $\gamma_{2}<1$ or $\gamma_{3}<\gamma_{2}^{2}$ then there is no distribution with positive support that is able to generate such moments (see Shohat and Tamarkin (1970); for example $\gamma_{2}<1$ would imply $\operatorname{Var}(v)<0$ ). Similar constraints must hold for the higher order moments. These tests are useful as specification tests, as they can be shown to be informative on the validity of the proportionality assumption (equation (4); see Abbring, Van den Berg and Van Ours (1994)).

\section{The data}

We use French administrative data on numbers of unemployed individuals in three age groups: youths (aged below 25), adults (aged 25-49) and elderly people (aged 50 and over), for both genders. These were collected by the French public employment offices (A.N.P.E.), and subsequently collected on a nation-wide scale by the Department of Labour. They cover individuals who are actively looking for full-time permanent jobs, and who are immediately available. The data are collected each quarter, and they allow for calculation of exit probabilities out of the first five quarterly duration classes, over the period 1982.IV-1994.IV. The latter time interval cannot be lengthened, because from 1995.I onwards the definitions of the administrative data changed substantially, causing an irreparable break in the series. Each quarter, a number of individuals move from one age group to another. We do not have data on these numbers, but their magnitude should be very small in comparison to the size of the inflow and outflow.

Unemployed individuals need to register at a public employment office in order to be eligible for unemployment benefits. However, since 1984, older unemployed individuals are exempted from seeking employment and registering. During the past decade, the age limit has been decreased from 57.5 to 55 years. As a result, we expect the data on elderly unemployed to be less informative. It is important to note that individuals may not only leave the unemployment statistics for employment. Participation in training schemes is an additional reason for exit, according to the employment offices.

Figure 1a shows the development of unemployment levels of male and female 
youths. The overall pattern is the same for both genders, male youth unemployment being lower than female youth unemployment. After a sharp rise in the early 1980s, a sharp decline sets in until 1990. The early 1990s show an increase again, but this increase is less modest for young men. This cyclical pattern is almost absent in the unemployment figures of adults (see Figure 1b). There we see a strong linear upward trend for both men and women. The levels of unemployment are more or less the same for adult men and women. The level of unemployment of the elderly is nearly constant over time, unemployment levels being higher for older men than for older women (see Figure 1c).

The graphs in Figures 1d-1f on the inflow size as a function of time resemble those for the unemployment levels. The inflow size for youths shows a downward trend, while the inflow size for adults is strongly upward trended. The inflow size for elderly is more or less constant. The trend for youths is caused by the declining participation rates for youths. This can be seen from Figures 1g-1i, where the inflow rate is graphed. The inflow rate is defined as the inflow size divided by the size ${ }^{2}$ of employment, for each age/gender group. ${ }^{3}$ From the figures it is clear that the inflow rate for youths is not downward trended. The inflow rate equals the probability of inflow into unemployment for a randomly-chosen employed participant. Therefore, this variable is more relevant for our purposes than the inflow size. In the next section we therefore focus on the inflow rates. In particular, $\psi_{4}(\tau)$ is estimated from inflow rate data.

The upward trend in the inflow size for adult women is also due to a certain extent to the increased participation rate of adult women (compare Figures 1e and 1h; note however from Figure $1 \mathrm{~h}$ that the inflow rates for male and female adults have both increased over time). The upward trended inflow size of adults and the downward trended inflow size of youths cause the share of youths in the inflow size to diminish over time. In 1983 the inflow size share of male (female) youths amounted to 52 (56) percent. By 1994, this share had shrunk to 29 (33) percent. The inflow size share of elderly during this period was more or less constant over time, being 7 (6) percent for men (women). In sum, the composition of the inflow

\footnotetext{
${ }^{2}$ We use labour force survey data from Eurostat to quantify the number of employed. These are based on a different definition of labour market states than the administrative data (Van den Berg and Van der Klaauw (1998)), but unfortunately we do not have employment size data based on the latter definition. The employment data are yearly, but as the number of employed is much larger than the inflow size, seasonal fluctuations in the employment size should not have a substantial effect on the inflow rate.

${ }^{3}$ The declining participation rate for youths is a typical French phenomenon; it reflects the extension of school attendance over this period (CSERC (1996)). The decline may be the result of a decision of youths to stay out of the labour market and enrol in further education because of the high risk of unemployment. It is not clear whether this is desirable or not.
} 
size has changed in terms of age. Note that if one would ignore the change in composition, and merge the data of all age groups together for a single empirical analysis, then the results would be biased.

Compared to other age groups, the inflow size for youths is high. For youths, $\widetilde{U}(0 \mid \tau)$ constitutes on average about 40 percent of total unemployment at a date $\tau$, whereas this is about 25 percent for adults and 15 percent for elderly workers. These numbers indicate a dynamic youth labour market. This is also conveyed by the empirical exit probabilities in the data. Figure 2 shows the relationship between empirical exit probabilities out of unemployment and unemployment duration, averaged over calendar time. Obviously, youths have the highest exit probabilities. The fact that inflow and outflow rates for youths are high is well documented (see the references in Section 1). High youth inflow rates may be due to the fact that many young workers are still searching for a good match. High youth outflow rates may be due to the fact that youths are flexible and have on average lower benefits. In France, both may also be due to a specific type of youth job contracts with little or no job protection. We return to this in the next section.

For youths and adults, the exit probability declines (non-monotonously) over the duration, while for the elderly it is more or less constant. There are small differences in the level of the exit probabilities for men and women in the first duration classes. For higher duration classes the exit probabilities are approximately the same across gender. The decline of the unemployment exit probability over the duration of unemployment can be due to unobserved heterogeneity, negative duration dependence, or a combination of both. The non-monotonicity on the other hand may be caused by the unemployment benefit system and a durationdependent flow into public employment programs.

In 1986, the procedure according to which the data are collected was changed. As a result, the time series on $\widetilde{U}(t \mid \tau)$ exhibit ruptures at 1986.IV. Further, the policy towards youth unemployment changed substantially in the mid-1980s as well, resulting in for instance the 1986 Emergency Plan for Youth Employment, mentioned in the introduction. For these reasons, we add to the model a dummy variable $d(\tau)$ equalling one if $\tau$ is after 1986.IV and zero otherwise. In particular, we multiply the expressions for $U(0 \mid \tau)$ and $\theta(0 \mid \tau)$ in the corresponding model equations by $\left(d_{\geq^{\prime} 87}\right)^{d(\tau)}$, in which $d_{\geq^{\prime} 87}$ is a parameter to be estimated. We do not impose this parameter to be the same in the equations for $U(0 \mid \tau)$ and $\theta(0 \mid \tau)$. 


\section{Estimation results}

\subsection{Preliminary issues}

Concerning the exit out of unemployment, we estimate a five-equation model for exit out of the first five duration classes (see equation (5)), for each gendertype and age group separately. The model expressions for $\theta(t \mid \tau)$ become very complicated for higher duration classes, and this complicates their use in the model estimation. However, below we show that the estimation results can in turn be used to make certain inferences on unemployment dynamics in higher duration classes. Estimation of incidence equation (6), using incidence observations $\widetilde{U}(0 \mid t)$, completes the analysis of unemployment dynamics. The model is estimated by Maximum Likelihood. The cyclical components in $\psi_{2}$ and $\psi_{4}$ are modeled using fifth-degree polynomials. ${ }^{4}$

It turns out that for the elderly we encountered problems in estimating the duration model, in particular the $\gamma_{i}$ parameters. As noted in Subsection 2.2, these parameters are identified from the interactions (or cross effects) of $t$ and $\tau$ in $\theta(t \mid \tau)$. The number of iterations required for the ML algorithm to converge was very large, as were the resulting standard errors of the $\gamma_{i}$ estimates. (This does not depend on the number of duration classes (i.e. on the number of equations used in the estimation.) As a result, we could not reject the null hypothesis that there is no unobserved heterogeneity among the elderly. This may be explained by the way the data on elderly are collected. As noted in Section 3, unemployed individuals older than 55 (previously 57.5) do not have to register in order to be eligible for unemployment benefits. Therefore, the administrative data only contain information on a subset of people who do not want to retire and expect that they will easier find a job by registering. We decided to estimate for the elderly a modified version of the duration model described in Subsection 2.2, not allowing for unobserved heterogeneity. Equation (4) then reduces to

$$
\theta(t \mid \tau, v)=\psi_{1}(t) \cdot \psi_{2}(\tau)
$$

where the functions $\psi_{1}$ and $\psi_{2}$ are parameterized as described in Subsection 2.3.

\footnotetext{
${ }^{4}$ According to statistical tests and graphical eyeball checks, the fit of the model is not improved by including higher-order polynomial terms.
} 


\subsection{Business cycles and the age-specific incidence of un- employment}

Tables 1, 2, and 3 present the estimates of the equation for the inflow rate into unemployment. Figures $3 \mathrm{a}$ and $3 \mathrm{~b}$ show the combined trend and cycle in the estimated inflow rate $\psi_{4}(\tau)$ (i.e., they show the estimated $\psi_{4}(\tau)$ evaluated at the average value of its seasonal component; the value on the vertical axis can be interpreted as the de-seasonalized quarterly probability that a randomly chosen employed worker becomes unemployed). The inflow rate is upward trended for adults and elderly, whereas there is no strong trend for youths. To compare the cyclical fluctuations across age groups and gender types, we filter out the trend, using a Hodrick-Prescott filter ${ }^{5}$. We then calculate the relative deviations from this trend. The results are shown in Figures $3 \mathrm{c}$ and $3 \mathrm{~d} .^{6}$

The capacity utilization ratio and Real GDP growth are conventional business cycle indicators. Figure 4 shows the development of these indicators for France over the period 1984.I-1994.IV. By comparing the capacity utilization ratio and Real GDP growth to the cyclical fluctuations in the incidence for men, it follows that, for all age groups, male incidence is counter-cyclical, while female incidence is hardly cyclical at all. The latter can be explained by a discouraged worker effect. Women who are not entitled to unemployment benefits may decide not to register at the ANPE during a recession, feeling that it is useless. They may therefore tend to stay non-participant. The strong cyclicality of male incidence can be explained by the fact that men are strongly represented in sectors that are sensitive to cyclical shocks (OECD (1996)), like manufacturing.

The inflow is most volatile for male youths. This, as well as the high level of the inflow for youths, can be explained by institutional features of the French labour market (see Cohen, Lefranc and Saint-Paul (1997), who observe high separation rates for French young workers in labour force survey data). In particular, one can distinguish between two types of employment contracts: short-term contracts of one year, renewable once, with inexpensive separation possibilities (CDDs or "contrats à durée determinée") on the one hand, and long-term contracts in which involuntary job termination is difficult (CDIs or "contrats à durée indeterminée") on the other. The short-term contracts are often used for young workers. Obviously, the workers with such contracts have a high inflow rate into unemployment.

\footnotetext{
${ }^{5}$ This smoothing method selects the trend path that minimizes the sum of the squared deviations, subject to the constraint that the sum of the squared second differences not be too large. This constraint determines the smoothness. We have set the smoothness parameter to the value 1600, as recommended in the literature, see Prescott (1996).

${ }^{6}$ The estimated relative fluctuations in the inflow size (not reported here) are virtually the same as in the inflow rate, as should be expected.
} 
This contributes to the high youth inflow rate. Cohen, Lefranc and Saint-Paul (1997) argue that youths thus bear the full burden of the increased flexibility of the French labour market. The option to be able to fire workers at low cost is particularly attractive for firms in a recession, so one may expect the inflow rate into unemployment for the corresponding workers to be particularly high during a recession. This is exactly what we find.

There is no systematic difference between the phases of the cycles for young men and adult men. Since 1988, the cycle for male youths seems to lag one year behind the cycle for adult men.

We finish this subsection with an examination of the estimated seasonal pattern in the incidence of unemployment. For youths, this is characterized by notably higher incidence in the second half of the year, probably caused by youths entering the labour market after leaving school. To obtain a closer look at the seasonal pattern in the inflow, we estimate a more general version of equation (7);

$$
\omega_{4}(\tau)=\exp \left\{\sum_{s=1}^{4}\left[\omega_{4 s}+\kappa_{s} d(\tau)\right] I_{s}(\tau)\right\}
$$

where $d(\tau)$ is a dummy variable equalling 1 if $\tau$ is after 1986.IV and 0 otherwise. We normalize $\omega_{41}=\kappa_{1}=0$, taking the first season as the base season. This equation incorporates an interaction effect between the policy dummy and the season. It turns out that the parameter estimates as reported in Table 1 hardly change. Furthermore, for women $\kappa_{3}$ and for men $\kappa_{2}$ and $\kappa_{3}$ are significant and negative. This suggests that the policy towards youth unemployment has had a dampening effect on the inflow rate of school leavers. For adults and elderly, the incidence of unemployment is not much affected by the season.

\subsection{Business cycles and the age-specific duration of un- employment}

The estimation results for the duration model are shown in Tables 4, 5, and 6 . In this subsection we focus on the estimates of the parameters of interest (i.e., those concerning calendar-time effects). Figures $5 \mathrm{a}$ and $5 \mathrm{~b}$ show the combined trend and cycle in the outflow ${ }^{7}$ Exit probabilities are on average higher for men than for women. Youths have on average the highest exit probabilities. (Note that the parameter $\mu_{1}$ can be interpreted as the average exit probability out of

\footnotetext{
${ }^{7}$ Precisely, they show the estimated $\psi_{2}(\tau)$ multiplied by $\mu_{1}$. This equals the exit probability out of the first duration class, evaluated at the average value of the seasonal effect on the exit probabilities, if the season of inflow is the first season.
} 
the first duration class. The estimate of this probability is much larger for youths than for adults.) Young workers are attractive because of the type of contract on which they can be hired. In addition, many young workers leave unemployment to special youth training and workfare programs. It is not clear whether the latter type of exits from unemployment are very attractive. Some of the workfare programs do not seem to provide much valuable work experience (Bonnal, Fougère and Sérandon (1997)). Also, some programs resemble regular employment, with the crucial difference that wages are allowed to be below the mandatory minimum wage for adults (Abowd et al. (1997)). From a study of individual labour market histories, Abowd et al. (1997) conclude that the individual probability of unemployment increases substantially at the moment at which the individual crosses the maximum age for these programs (usually 25 years). In sum, the youth outflow rate level by itself may suggest a rosier picture than warranted by the positions taken after exit out of unemployment and long-run prospects in general.

The outflow rates for adults seem to be rather strongly downward trended. Figures $5 \mathrm{c}$ and $5 \mathrm{~d}$ show the relative deviations from the trend, for each age group. The pattern described by the deviations resembles the pattern described by the conventional business cycle indicators (see Figure 4), so the exit probabilities are pro-cyclically affected. A striking result is that the exit probabilities of young workers are less affected by the cycle than those of adult workers. This is actually in agreement with the importance of youth job contracts. In a recession, hiring young workers is relatively attractive in comparison to hiring adult workers, for the reason that the former can be fired easily. In other words, the main advantage of hiring youths in a recession is not that they can be hired so easily but rather that they can be fired so easily.

The phase of the cycle differs between men and women. For men, the turning points are about a half to one year earlier in time than they are for women. This can be explained by the fact that men are over-represented in sectors that are sensitive to cyclical shocks from abroad, like manufacturing sectors, which are leading sectors in economic cycles. Women predominantly work in service sectors.

The seasonal effect on the outflow works by way of a direct effect on the outflow probabilities, and by way of an indirect effect on the composition of the inflow. The direct seasonal effect on the outflow probabilities of youths is small. Adults and elderly experience a strong negative effect in the fourth quarter, relative to the first quarter. The indirect seasonal effect on the composition of the inflow is similar for youths and adults. (Remember we do not estimate this effect for elderly.) Individuals who become unemployed in the second half of the year have more success in leaving unemployment quickly. 


\subsection{The other parameter estimates}

In this subsection we briefly discuss the estimates of the other model parameters, most of which are included into the model in order to ensure that the calendartime effect parameters are correctly estimated.

The parameter $\gamma_{2}$ by definition equals $1+\operatorname{Var}(v) / E(v)^{2}$. Therefore, if the estimate of $\gamma_{2}$ does not significantly differ from 1 , there is no unobserved heterogeneity. This is the case for youths. The moments of the unobserved heterogeneity distribution $G(v)$ are consistent with a degenerate distribution in $v=\mu_{1}$. Note that this does not mean that all youths are the same; it merely means that they do not have significantly different individual exit probabilities. It should be noted that this result may be sensitive to the proportionality assumption (4) and to the assumption that the rupture in the data at 1986.IV is due to external factors. We return to this below.

For male adults, the moment-inequalities imply a discrete distribution with two positive points of support. The unobserved heterogeneity of female adults, on the other hand, can be described by a discrete distribution with three positive points of support. ${ }^{8}$ Note that for both age groups we have found distributions that are consistent with the estimated normalized moments. This supports the MPH specification.

The duration dependence parameter estimates for youths indicate a nonmonotonous but insignificant dependence. Testing the null hypothesis $\psi_{1 i}=$ $0,(i=1,2,3,4)$, the Wald statistic is 6.0 for women and 8.1 for men. Therefore, for both male and female youths the null hypothesis is not rejected at a 5 percent significance level. For adults and elderly we find significant positive duration dependence during the first five quarters of unemployment. This dependence is strongest for women. As a result, stigma effects do not seem to play a dominant role during the first five quarters of unemployment.

Our empirical analysis so far has been based on the exit probabilities out of the first five quarters of unemployment. We now present a procedure to extend

\footnotetext{
${ }^{8}$ This suggests that the variation across female adults is larger than across male adults, and this is confirmed by the higher value of the estimate of $\gamma_{2}$ for female adults. It may be interesting to infer the specification of the implied discrete unobserved heterogeneity distribution. For male adults it turns out that $86 \%$ of the inflow into unemployment has a heterogeneity value equal to 0.80 times the mean $\mu_{1}$ of the distribution, and $14 \%$ has a heterogeneity value equal to 2.27 times this mean (so $\operatorname{Pr}\left(v=0.80 \mu_{1}\right)=0.86$ and $\operatorname{Pr}\left(v=2.27 \mu_{1}\right)=0.14$ ). For adult women, $\operatorname{Pr}\left(v=0.22 \mu_{1}\right)=0.24, \operatorname{Pr}\left(v=1.09 \mu_{1}\right)=0.70, \operatorname{Pr}\left(v=3.31 \mu_{1}\right)=0.05$. Thus, among female adults, there is a small subgroup with a very large exit probability. Among adult men, the group with a very high exit probability is a somewhat larger. The individuals in these groups disappear rapidly from unemployment, as the duration proceeds.
} 
this analysis to higher duration classes. As argued above, unobserved heterogeneity can be characterized by a discrete distribution. Assuming these implied distributions are the true distributions, we can extend our empirical analysis to higher duration classes without much computational burden. Along this line, we estimate the $\psi_{1 i}$ parameters, for $i=5, . ., 17$, using data on exit probabilities for 19 (quarterly) duration classes, fixing the other parameters on their estimated values in the 5-equation duration model. The results are shown in Figures 6a and $6 \mathrm{~b}$. All age groups show negative duration dependence after 4 quarters of unemployment. The duration dependence of youths and elderly is moderate. After 13 quarters of unemployment the individual exit probabilities of both groups increase. This may be due to the expiration of benefits or by an artefact of the data collection procedure (the small number of unemployed in these high duration classes causes the exit probability to be inexactly measured). The latter explanation is supported by the fact that the effect does not show up for adults, who constitute the largest group and as such are relatively abundant in the higher duration classes.

The measurement errors all have a standard deviation close to 0.04, and they are positively correlated across duration classes at one calendar moment. From this we conclude that the model fits the data well, and that misclassification of unemployed individuals into adjacent duration classes is not a major source of errors in the observed unemployment figures. The estimates of $d_{\geq^{\prime} 87}$ indicate a significant positive effect for all gender types and age groups. This effect varies between 5 and 15 percent for the incidence equation and between 11 and 18 percent for the equation for $\theta(0 \mid \tau)$. There is not much difference across genders. Also, the effect is not larger for youths than for adults. This suggests that the significant effect of the dummy variable is not caused by policy towards youth employment, but rather by the changes in the data collection procedure.

\section{Conclusions}

In France, like in many other Western European countries, both the level and the turnover of youth unemployment are high in comparison to adult unemployment. In this paper we have examined the dynamics of age- and gender-specific unemployment, by estimating the calendar-time behaviour of the unemployment inflow and outflow rates, taking account of duration dependence, individual heterogeneity, and seasonality in the data. For youths, there does not appear to be a strong long-run trend in the inflow or outflow rates. The inflow size has decreased for youths and for adult women, but this is a consequence of the declining partic- 
ipation rates for these groups. For adults, the inflow rates have increased, and the outflow rates have decreased. In this sense, youths fared better than adults during the past decades. However, this is to a certain extent due to the special youth training and workfare programs, and it is not always clear that these improve the long-run labour market prospects of youths.

Concerning cyclical effects, it turns out that in general the inflow rate is counter-cyclical whereas the outflow rate is pro-cyclical. For women, the cycles in the inflow rate are not pronounced. This may be due to a discouraged worker effect during recessions, and to a lower incentive to register as unemployed. The strong cyclicality of the male inflow rate can be explained by the fact that men are strongly represented in sectors that are sensitive to cyclical shocks. For men, the cycle in the inflow rate is somewhat larger for youths than for adults. For both men and women, the cycle in the outflow is somewhat smaller for youths. The volatility of the youth unemployment rate can thus be attributed to the volatility of the youth inflow rate, whereas for adults the opposite is closer to the truth.

Many differences in cyclical behaviour between (male) youths and (male) adults can be explained by institutional features of the French labour market. Young workers are often employed in jobs with short-term contracts or in training or workfare programs. The former can be argued to contribute to the high youth inflow and outflow rates, the volatility of the youth inflow rate, and the lack of volatility of the youth outflow rate. The latter programs can be argued to contribute to the high youth outflow rates.

There is no systematic difference between the phases of the inflow cycles for young men and adult men. Since 1988, the cycle for male youths seems to lag one year behind the cycle for adult men, but before 1988 the ordering is reversed. From the other parameter estimates, the most important result concerns the negative duration dependence of the youth exit probability after a year of unemployment.

These results imply some policy suggestions. As explained in the introduction to this paper, long-term youth unemployment is very undesirable. A given young individual in the inflow has the highest probability of becoming long-term unemployed if he enters unemployment in a recession. Moreover, youth inflow is highest during a recession, and youth exit probabilities are negatively duration dependent. Thus, policy against long-term youth unemployment should focus on unemployed youths in a recession who have been unemployed for more than a year. Another result with some relevance for policy concerns the fact that it could not be unambiguously established that the adult inflow rate is a leading indicator of the youth inflow rate.

Finally, our results highlight the importance of seasonal fluctuations. Here we find some major differences between youth and adult unemployment. These 
differences are related to the inflow into unemployment. The large seasonal fluctuations in youth unemployment are to a large extent driven by fluctuations in the inflow that are presumably caused by the large number of school leavers entering the labour market in the third quarter of the year. 


\section{References}

Abowd, J.M., F. Kramarz, T. Lemieux, and D.N. Margolis (1997), "Minimum wages and employment in France and the United States", Working paper, CREST-INSEE, Paris.

Abbring, J.H., G.J. van den Berg, and J.C. van Ours (1994), "The anatomy of unemployment dynamics", Working paper, Tinbergen Institute.

Baker, M. (1992), "Unemployment duration: compositional effects and cyclical variability", American Economic Review, 82, 313-321.

Bonnal, L., D. Fougère, and A. Sérandon (1997), "Evaluating the impact of French employment policies on individual labour market histories", Review of Economic Studies, 64, 683-713.

Butler, R.J. and J.B. MacDonald (1986), "Trends in unemployment duration data", Review of Economics and Statistics, 68, 545-557.

Clark, K.B. and L.H. Summers (1982), "The dynamics of youth unemployment", in R. Freeman and D. Wise, editors, The Youth Labor Market Problem, 199234, University of Chicago Press.

Cohen, D., A. Lefranc, and G. Saint-Paul (1997), "French unemployment: A transatlantic perspective", Economic Policy, 25, 265-292.

CSERC (1996), Inégalités d'Emploi et de Revenu: Les Années quatre-vingt-dix, CSERC, Paris.

Devine, T.J. and N.M. Kiefer (1991), Empirical Labor Economics, Oxford University Press, New York.

Dynarski, M. and S.M. Sheffrin (1990), "The behavior of unemployment durations over the cycle", Review of Economics and Statistics, 72, 350-356.

Layard, R., S. Nickell, and R. Jackman (1991), Unemployment, Oxford University Press, Oxford.

Lynch, L.M. (1985), "State dependency in youth unemployment. A lost generation?", Journal of Econometrics, 28, 71-84.

Lynch, L.M. (1989), "The youth labor market in the eighties: Determinants of reemployment probabilities for young men and women.", Review of Economics and Statistics, 71, 37-45.

OECD (1983), Employment Outlook 1983, OECD, Paris.

OECD (1984a), The nature of youth unemployment. An analysis for policy makers, OECD, Paris. 
OECD (1984b), Youth employment in France. Recent strategies, OECD, Paris.

OECD (1995), Labour Force Statistics 1973-1993, OECD, Paris.

OECD (1996), Employment Outlook 1996, OECD, Paris.

Prescott, E.C. (1996), "Theory ahead of business cycle measurement", in Quarterly Review, 9-22, Federal Reserve Bank of Minneapolis.

Shohat, J.A. and J.D. Tamarkin (1970), The problem of moments, American Mathematical Society, Providence.

Sider, H. (1985), "Unemployment duration and incidence: 1968-82", American Economic Review, 75, 461-472.

Van den Berg, G.J. and J.C. van Ours (1996), "Unemployment dynamics and duration dependence", Journal of Labor Economics, 14, 100-125.

Van den Berg, G.J. and B. van der Klaauw (1998), "Combining micro and macro unemployment duration data", Working paper, Free University, Amsterdam. 
Table 1. Parameter estimates incidence. Age group $<25$.

(Standard errors in parentheses)

\begin{tabular}{|l|cc|cc|}
\hline & \multicolumn{2}{|c|}{ Men } & Women \\
\hline \multicolumn{5}{|c|}{ Estimates } \\
\hline \multicolumn{5}{|c|}{ constant } \\
\hline$c$ & -2.487 & $(0.027)$ & -2.486 & $(0.028)$ \\
\hline \multicolumn{5}{|l|}{ cycle } \\
\hline$\alpha_{14}$ & 0.033 & $(0.027)$ & 0.003 & $(0.028)$ \\
$\alpha_{24}$ & 0.115 & $(0.012)$ & 0.079 & $(0.013)$ \\
$\alpha_{34}$ & 0.092 & $(0.011)$ & 0.053 & $(0.012)$ \\
$\alpha_{44}$ & -0.049 & $(0.012)$ & -0.020 & $(0.012)$ \\
$\alpha_{54}$ & -0.027 & $(0.010)$ & 0.004 & $(0.010)$ \\
\hline season & -0.112 & $(0.018)$ & 0.058 & $(0.018)$ \\
\hline$\omega_{24}$ & 0.442 & $(0.018)$ & 0.694 & $(0.018)$ \\
$\omega_{34}$ & 0.364 & $(0.018)$ & 0.339 & $(0.018)$ \\
$\omega_{44}$ & 0.040 \\
\hline measurement error & \\
\hline$\sigma$ & 0.044 & $(0.004)$ & 0.044 & $(0.004)$ \\
$d_{\geq \prime 87}$ & 1.124 & $(0.043)$ & 1.176 & $(0.046)$ \\
\hline \multicolumn{5}{|c}{} \\
\hline
\end{tabular}


Table 2. Parameter estimates incidence. Age group 25-49.

(Standard errors in parentheses)

\begin{tabular}{|l|cc|cc|}
\hline & \multicolumn{3}{|c|}{ Men } & Women \\
\hline \multicolumn{5}{|c|}{ Estimates } \\
\hline \multicolumn{5}{|l|}{ constant } \\
\hline$c$ & -3.789 & $(0.024)$ & -3.654 & $(0.021)$ \\
\hline \multicolumn{5}{|l|}{ cycle } \\
\hline$\alpha_{14}$ & 0.159 & $(0.021)$ & 0.249 & $(0.016)$ \\
$\alpha_{24}$ & 0.033 & $(0.010)$ & -0.050 & $(0.008)$ \\
$\alpha_{34}$ & 0.005 & $(0.009)$ & -0.043 & $(0.008)$ \\
$\alpha_{44}$ & -0.032 & $(0.009)$ & 0.013 & $(0.008)$ \\
$\alpha_{54}$ & -0.028 & $(0.008)$ & 0.006 & $(0.006)$ \\
\hline season & \multicolumn{5}{|l}{} \\
\hline$\omega_{24}$ & -0.151 & $(0.015)$ & -0.097 & $(0.012)$ \\
$\omega_{34}$ & 0.008 & $(0.015)$ & 0.119 & $(0.012)$ \\
$\omega_{44}$ & 0.127 & $(0.015)$ & 0.064 & $(0.012)$ \\
\hline measurement error \\
\hline$\sigma$ & 0.035 & $(0.004)$ & 0.029 & $(0.003)$ \\
$d_{\geq}^{\prime} 87$ & 1.096 & $(0.034)$ & 1.094 & $(0.028)$ \\
\hline
\end{tabular}


Table 3. Parameter estimates incidence. Age group 50+. (Standard errors in parentheses)

\begin{tabular}{|l|cc|cc|}
\hline & \multicolumn{3}{|c|}{ Men } & Women \\
\hline \multicolumn{5}{|c|}{ Estimates } \\
\hline \multicolumn{5}{|l|}{ constant } \\
\hline$c$ & -4.372 & $(0.034)$ & -4.474 & $(0.025)$ \\
\hline cycle & $(0.030)$ & 0.124 & $(0.021)$ \\
\hline$\alpha_{14}$ & 0.081 & $(0.014)$ & -0.064 & $(0.011)$ \\
$\alpha_{24}$ & -0.017 & $(0.013)$ & -0.020 & $(0.010)$ \\
$\alpha_{34}$ & -0.003 & $(0.014)$ & -0.017 & $(0.010)$ \\
$\alpha_{44}$ & -0.066 & $(0.011)$ & -0.001 & $(0.008)$ \\
$\alpha_{54}$ & -0.033 & $(0.021)$ & -0.105 & $(0.015)$ \\
\hline season & \multicolumn{5}{|c|}{} \\
\hline$\omega_{24}$ & -0.144 & $(0.02)$ & -0.052 & $(0.015)$ \\
$\omega_{34}$ & -0.119 & $(0.021)$ & $(0.015)$ \\
$\omega_{44}$ & 0.022 & $(0.021)$ & 0.017 & \\
\hline measurement error & & \\
\hline$\sigma$ & 0.051 & $(0.005)$ & 0.037 & $(0.004)$ \\
$d_{\geq \prime} 87$ & 1.184 & $(0.054)$ & 1.098 & $(0.036)$ \\
\hline
\end{tabular}


Table 4. Parameter estimates duration. Age group $<25$.

(Standard errors in parentheses)

\begin{tabular}{|c|c|c|c|c|}
\hline & \multicolumn{2}{|c|}{ Men } & \multicolumn{2}{|c|}{ Women } \\
\hline & \multicolumn{4}{|c|}{ Estimates } \\
\hline \multicolumn{5}{|c|}{ unobserved heterogeneity } \\
\hline$\mu_{1}$ & 0.445 & $(0.009)$ & 0.351 & $(0.009)$ \\
\hline$\gamma_{2}$ & 1.037 & $(0.029)$ & 1.031 & $(0.054)$ \\
\hline$\gamma_{3}$ & 1.155 & $(0.136)$ & 1.066 & $(0.279)$ \\
\hline$\gamma_{4}$ & 1.452 & $(0.514)$ & 1.260 & $(1.282)$ \\
\hline$\gamma_{5}$ & 2.117 & $(1.778)$ & 2.825 & $(5.554)$ \\
\hline \multicolumn{5}{|c|}{ duration dependence } \\
\hline$\psi_{11}$ & 0.021 & $(0.030)$ & 0.007 & $(0.037)$ \\
\hline$\psi_{12}$ & -0.061 & $(0.049)$ & -0.034 & $(0.069)$ \\
\hline$\psi_{13}$ & -0.097 & $(0.058)$ & 0.030 & $(0.083)$ \\
\hline$\psi_{14}$ & -0.053 & $(0.063)$ & 0.066 & $(0.097)$ \\
\hline \multicolumn{5}{|c|}{ cycle outflow } \\
\hline$\alpha_{12}$ & -0.062 & $(0.009)$ & -0.036 & $(0.010)$ \\
\hline$\alpha_{22}$ & -0.051 & $(0.007)$ & -0.044 & $(0.008)$ \\
\hline$\alpha_{32}$ & -0.025 & $(0.007)$ & -0.062 & $(0.009)$ \\
\hline$\alpha_{42}$ & 0.063 & $(0.006)$ & 0.041 & $(0.007)$ \\
\hline$\alpha_{52}$ & -0.001 & $(0.005)$ & -0.006 & $(0.007)$ \\
\hline \multicolumn{5}{|c|}{ season outflow } \\
\hline$\omega_{22}$ & -0.132 & $(0.030)$ & -0.035 & $(0.036)$ \\
\hline$\omega_{32}$ & -0.085 & $(0.024)$ & 0.010 & $(0.030)$ \\
\hline$\omega_{42}$ & 0.041 & $(0.025)$ & 0.147 & $(0.032)$ \\
\hline \multicolumn{5}{|c|}{ season composition inflow } \\
\hline$\omega_{23}$ & -0.012 & $(0.005)$ & 0.003 & $(0.006)$ \\
\hline$\omega_{33}$ & 0.018 & $(0.007)$ & 0.012 & $(0.010)$ \\
\hline$\omega_{43}$ & 0.034 & $(0.008)$ & 0.035 & $(0.011)$ \\
\hline \multicolumn{5}{|c|}{ measurement error } \\
\hline$\sigma$ & 0.042 & $(0.003)$ & 0.037 & $(0.003)$ \\
\hline$\rho$ & 0.614 & $(0.055)$ & 0.649 & $(0.059)$ \\
\hline$d_{\geq \prime 87}$ & 1.123 & $(0.018)$ & 1.112 & $(0.021)$ \\
\hline \multirow{2}{*}{\multicolumn{3}{|c|}{ Moment-inequality statistics }} & (Wald w & t. 0$)$ \\
\hline & & & Men & Women \\
\hline \multicolumn{3}{|c|}{$\gamma_{2}-1$} & 1.283 & 0.576 \\
\hline \multicolumn{3}{|c|}{$\gamma_{3}-\gamma_{2}^{2}$} & 0.920 & 0.013 \\
\hline \multicolumn{3}{|c|}{$\gamma_{2} \gamma_{4}-\gamma_{3}^{2}-\gamma_{4}-\gamma_{2}^{3}+2 \gamma_{2} \gamma_{3}$} & 0.103 & 0.172 \\
\hline \multicolumn{3}{|c|}{$\gamma_{3} \gamma_{5}-\gamma_{4}^{2}-\gamma_{2}^{2} \gamma_{5}-\gamma_{3}^{2}+2 \gamma_{2} \gamma_{3} \gamma_{4}$} & -0.228 & -0.218 \\
\hline
\end{tabular}


Table 5. Parameter estimates duration. Age group 25-49.

(Standard errors in parentheses)

\begin{tabular}{|c|c|c|c|c|}
\hline & \multicolumn{2}{|c|}{ Men } & \multicolumn{2}{|l|}{ Women } \\
\hline & \multicolumn{4}{|c|}{ Estimates } \\
\hline \multicolumn{5}{|c|}{ unobserved heterogeneity } \\
\hline$\mu_{1}$ & 0.321 & $(0.007)$ & 0.252 & $(0.007)$ \\
\hline$\gamma_{2}$ & 1.260 & $(0.059)$ & 1.445 & $(0.069)$ \\
\hline$\gamma_{3}$ & 2.056 & $(0.296)$ & 2.902 & $(0.374)$ \\
\hline$\gamma_{4}$ & 3.883 & $(1.252)$ & 7.600 & $(1.754)$ \\
\hline$\gamma_{5}$ & 6.308 & $(5.311)$ & 22.599 & $(8.064)$ \\
\hline \multicolumn{5}{|c|}{ duration dependence } \\
\hline$\psi_{11}$ & 0.124 & $(0.033)$ & 0.230 & $\overline{(0.032)}$ \\
\hline$\psi_{12}$ & 0.094 & $(0.052)$ & 0.241 & $(0.055)$ \\
\hline$\psi_{13}$ & 0.091 & $(0.062)$ & 0.352 & $(0.068)$ \\
\hline$\psi_{14}$ & 0.173 & $(0.068)$ & 0.534 & $(0.077)$ \\
\hline \multicolumn{5}{|c|}{ cycle outflow } \\
\hline$\alpha_{12}$ & -0.177 & $(0.012)$ & -0.191 & $\overline{(0.016)}$ \\
\hline$\alpha_{22}$ & -0.001 & $(0.007)$ & -0.058 & $(0.012)$ \\
\hline$\alpha_{32}$ & -0.040 & $(0.008)$ & -0.126 & $(0.012)$ \\
\hline$\alpha_{42}$ & 0.077 & $(0.006)$ & 0.052 & $(0.009)$ \\
\hline$\alpha_{52}$ & 0.033 & $(0.006)$ & 0.035 & $(0.009)$ \\
\hline \multicolumn{5}{|c|}{ season outflow } \\
\hline$\omega_{22}$ & -0.070 & $(0.029)$ & -0.055 & $(0.037)$ \\
\hline$\omega_{32}$ & -0.081 & $(0.025)$ & 0.034 & $(0.030)$ \\
\hline$\omega_{42}$ & -0.261 & $(0.031)$ & -0.279 & $(0.041)$ \\
\hline \multicolumn{5}{|c|}{ season composition inflow } \\
\hline$\omega_{23}$ & -0.014 & $(0.005)$ & -0.006 & $(0.007)$ \\
\hline$\omega_{33}$ & 0.019 & $(0.006)$ & 0.030 & $(0.007)$ \\
\hline$\omega_{43}$ & 0.054 & $(0.005)$ & 0.050 & $(0.007)$ \\
\hline \multicolumn{5}{|c|}{ measurement error } \\
\hline $\bar{\sigma}$ & 0.025 & $(0.002)$ & 0.025 & $(0.002)$ \\
\hline$\rho$ & 0.732 & $(0.051)$ & 0.761 & $(0.048)$ \\
\hline$d_{\geq \prime 87}$ & 1.137 & $(0.017)$ & 1.179 & $(0.026)$ \\
\hline \multirow{2}{*}{\multicolumn{3}{|c|}{ Moment-inequality statistics }} & (Wald w.r & t. 0$)$ \\
\hline & & & Men & Women \\
\hline \multicolumn{3}{|c|}{$\gamma_{2}-1$} & 4.366 & 6.500 \\
\hline \multicolumn{3}{|c|}{$\gamma_{3}-\gamma_{2}^{2}$} & 2.880 & 3.965 \\
\hline \multicolumn{3}{|c|}{$\gamma_{2} \gamma_{4}-\gamma_{3}^{2}-\gamma_{4}-\gamma_{2}^{3}+2 \gamma_{2} \gamma_{3}$} & -0.703 & 2.276 \\
\hline \multicolumn{3}{|c|}{$\gamma_{3} \gamma_{5}-\gamma_{4}^{2}-\gamma_{2}^{2} \gamma_{5}-\gamma_{3}^{2}+2 \gamma_{2} \gamma_{3} \gamma_{4}$} & -1.522 & -0.119 \\
\hline
\end{tabular}


Table 6. Parameter estimates duration. Age group 50+. (Standard errors in parentheses)

\begin{tabular}{|c|c|c|c|c|}
\hline & \multicolumn{2}{|c|}{ Men } & \multicolumn{2}{|c|}{ Women } \\
\hline & \multicolumn{4}{|c|}{ Estimates } \\
\hline \multicolumn{5}{|c|}{ duration dependence } \\
\hline$\psi_{11}$ & 0.240 & $(0.057)$ & 0.467 & $(0.080)$ \\
\hline$\psi_{12}$ & 0.059 & $(0.060)$ & 0.193 & $(0.088)$ \\
\hline$\psi_{13}$ & 0.150 & $(0.057)$ & 0.254 & $(0.083)$ \\
\hline$\psi_{14}$ & 0.274 & $(0.056)$ & 0.335 & $(0.082)$ \\
\hline \multicolumn{5}{|c|}{ cycle outflow } \\
\hline$\overline{\alpha_{02}}$ & 0.156 & $(0.011)$ & 0.127 & $\overline{(0.013)}$ \\
\hline$\alpha_{12}$ & 0.013 & $(0.004)$ & 0.014 & $(0.004)$ \\
\hline$\alpha_{22}$ & 0.001 & $(0.003)$ & 0.008 & $(0.003)$ \\
\hline$\alpha_{32}$ & 0.006 & $(0.003)$ & 0.000 & $(0.003)$ \\
\hline$\alpha_{42}$ & 0.016 & $(0.003)$ & 0.008 & $(0.003)$ \\
\hline$\alpha_{52}$ & 0.005 & $(0.003)$ & 0.005 & $(0.003)$ \\
\hline \multicolumn{5}{|c|}{ season outflow } \\
\hline$\omega_{22}$ & -0.249 & $\overline{(0.100)}$ & -0.359 & $\overline{(0.171)}$ \\
\hline$\omega_{32}$ & -0.051 & $(0.059)$ & -0.037 & $(0.070)$ \\
\hline$\omega_{42}$ & -0.467 & $(0.107)$ & -0.829 & $(0.150)$ \\
\hline \multicolumn{5}{|c|}{ measurement error } \\
\hline$\sigma$ & 0.036 & $(0.003)$ & 0.036 & $(0.004)$ \\
\hline$\rho$ & 0.703 & $(0.062)$ & 0.650 & $(0.102)$ \\
\hline$d_{\geq^{\prime} 87}$ & 1.379 & $(0.081)$ & 1.631 & $(0.137)$ \\
\hline
\end{tabular}


1a. Unemployment in France, youths

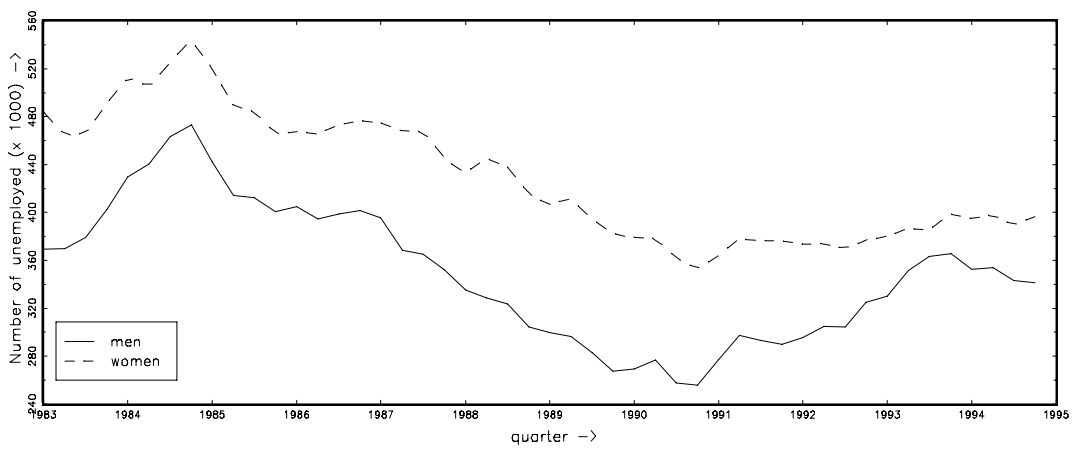

1b. Unemployment in France, adults

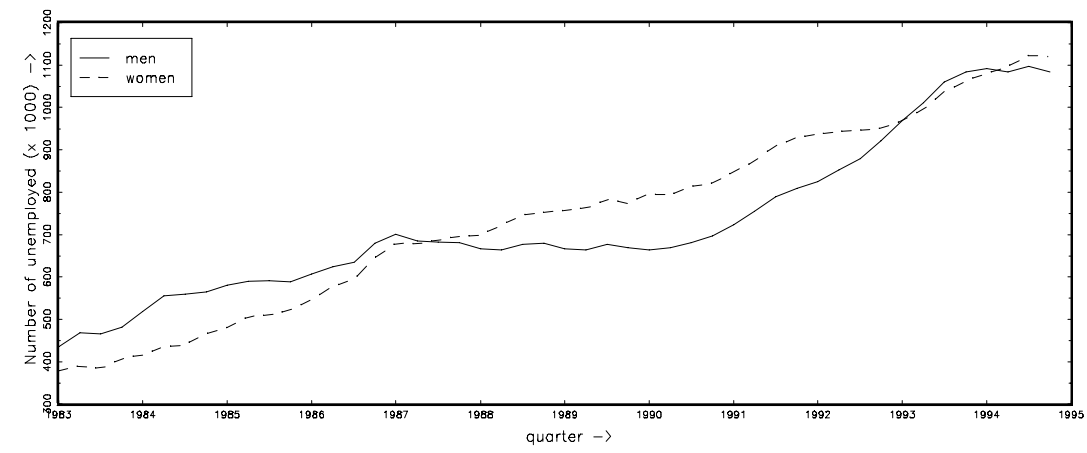

1c. Unemployment in France, elderly

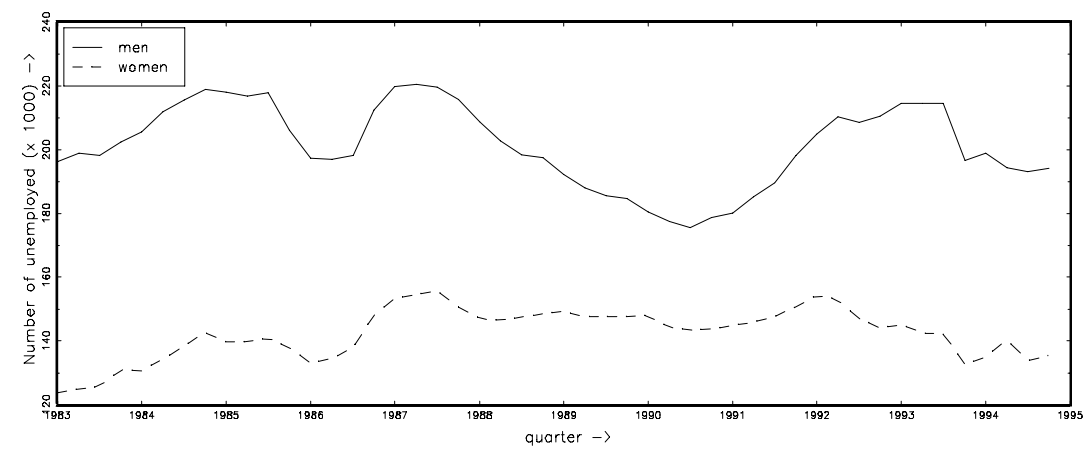


1d. Inflow into unemployment, youths

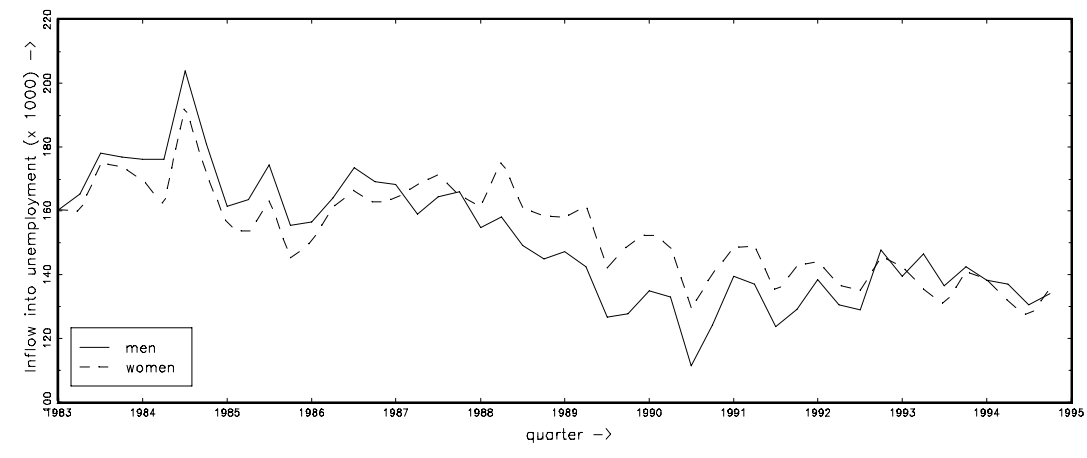

1e. Inflow into unemployment, adults

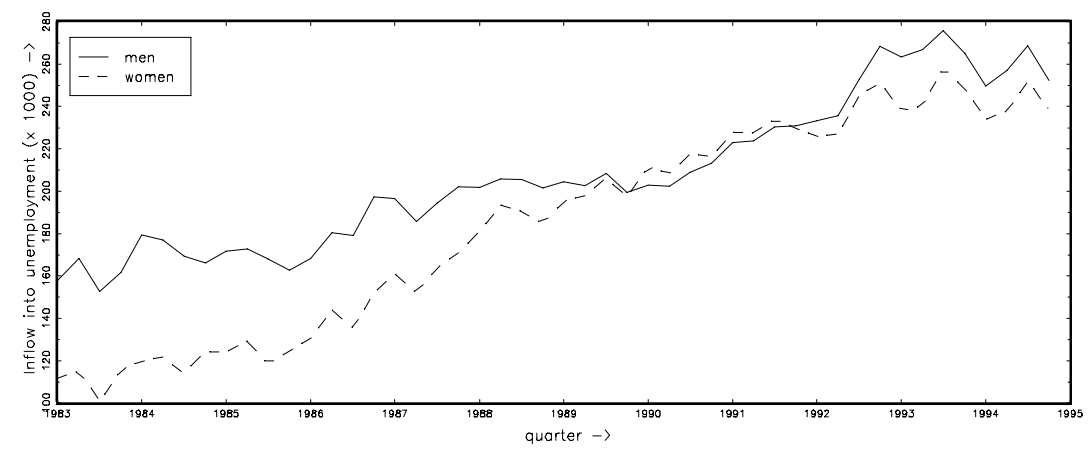

1f. Inflow into unemployment, elderly

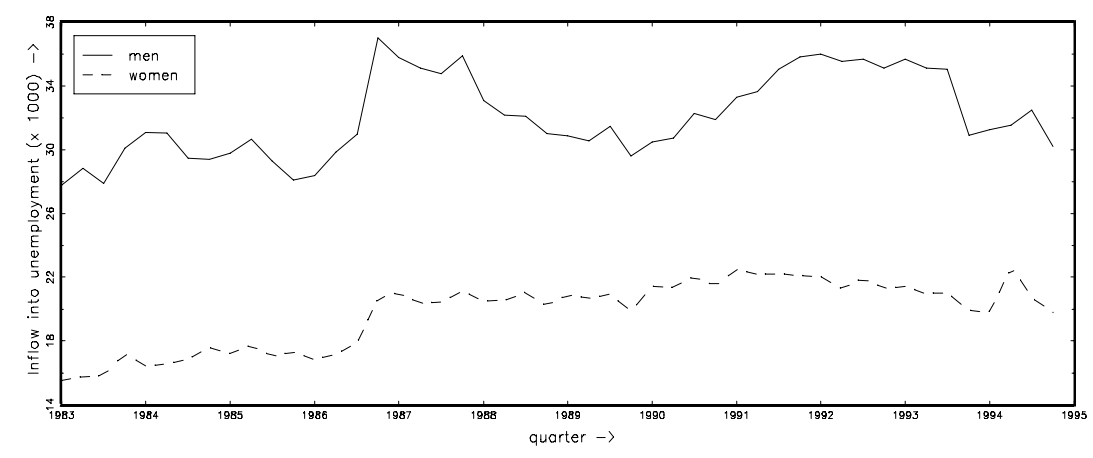


1g. Inflow / number of employed, youths

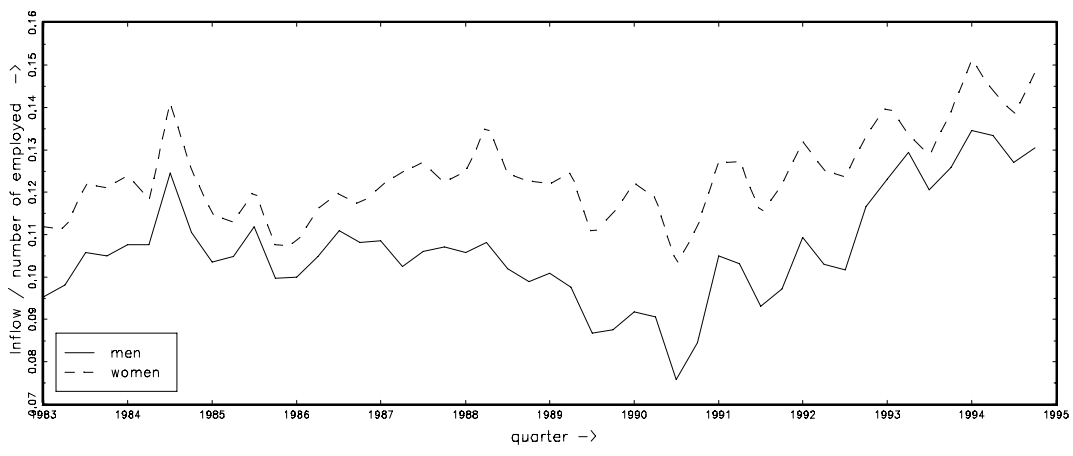

1h. Inflow / number of employed, adults

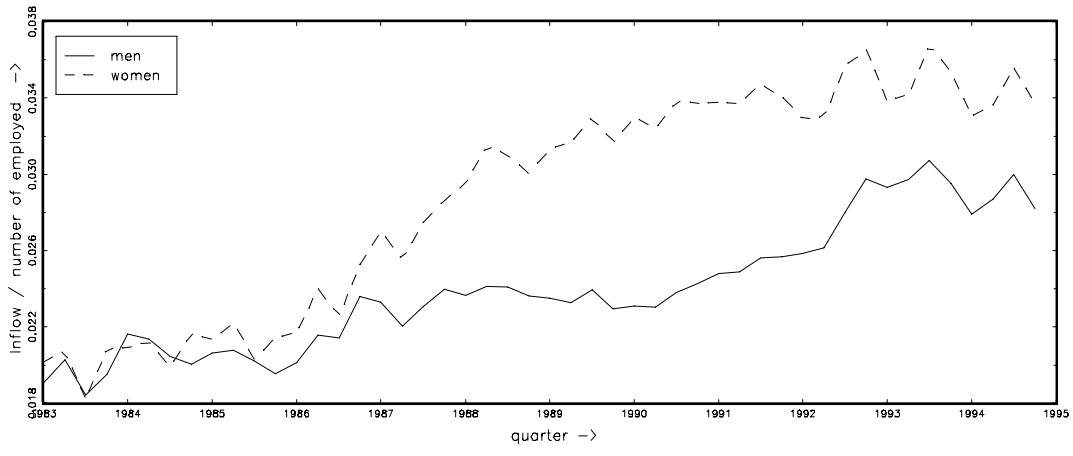

1i. Inflow / number of employed, elderly

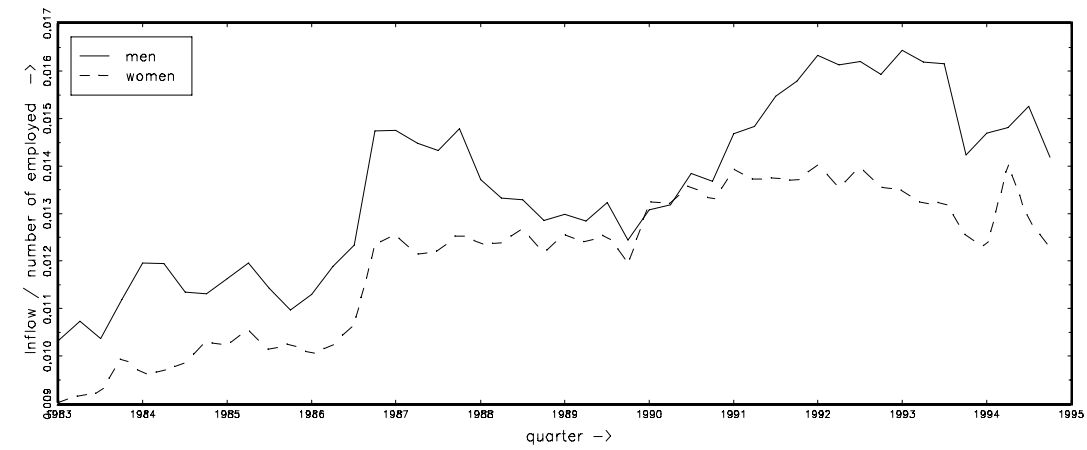


2a. Average quarterly exit probability, men

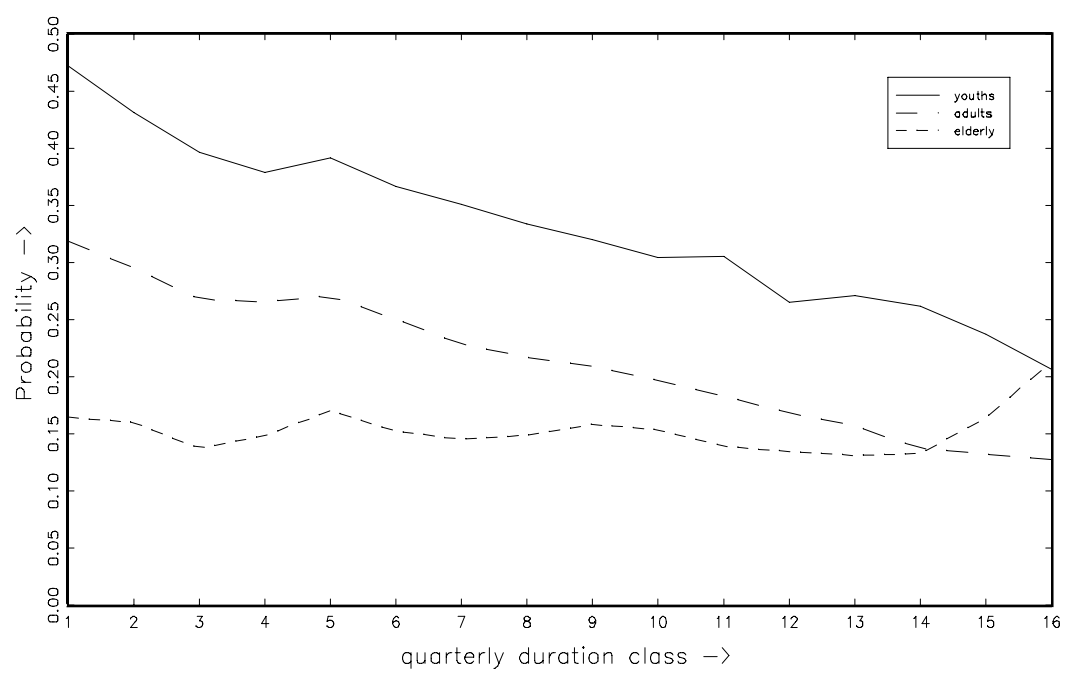

2b. Average quarterly exit probability, women

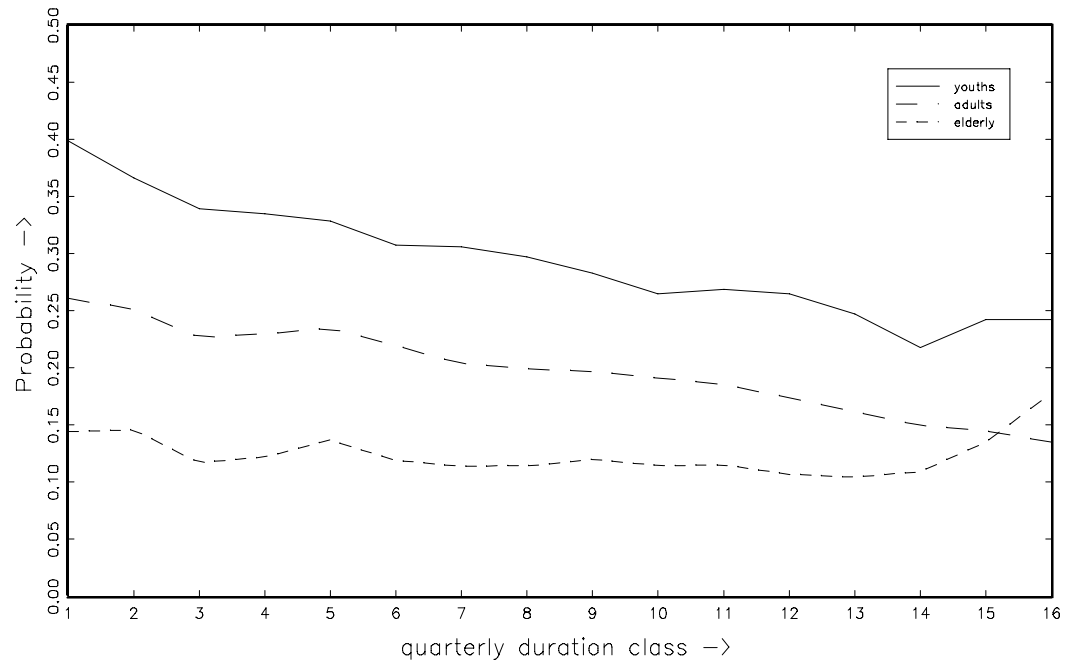


3a. Cycle incidence / \# employed, womer

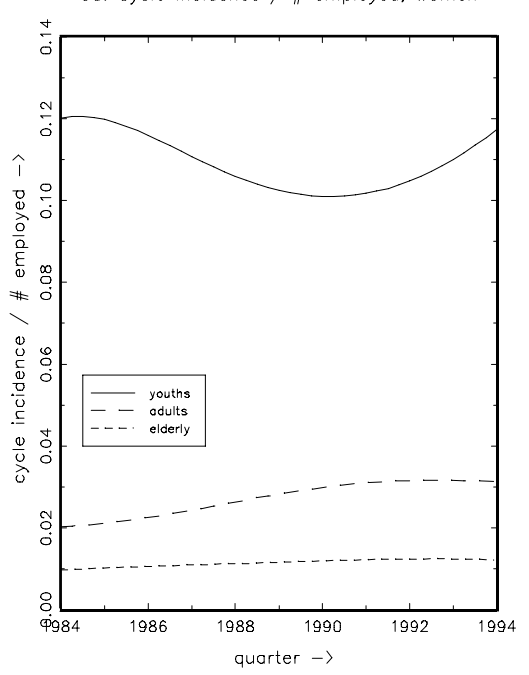

3c. Relative deviation from trend, women

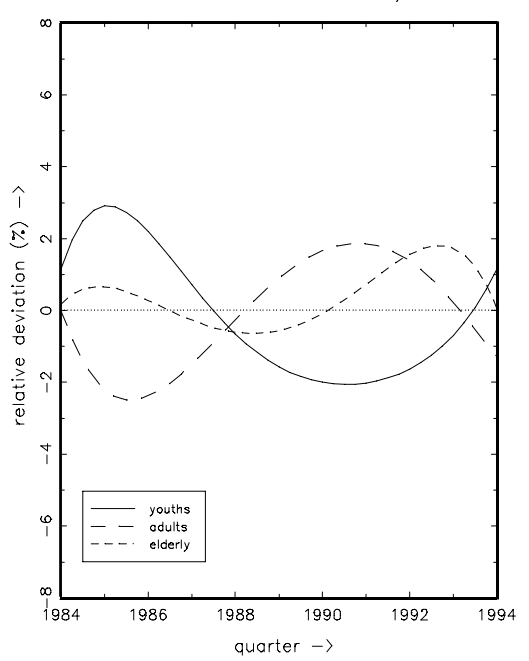

3b. Cycle incidence / \# employed, mer

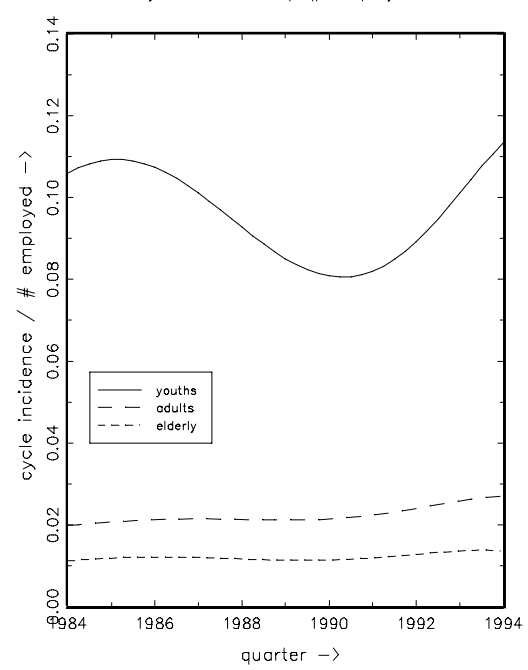

3d. Relative deviation from trend, men

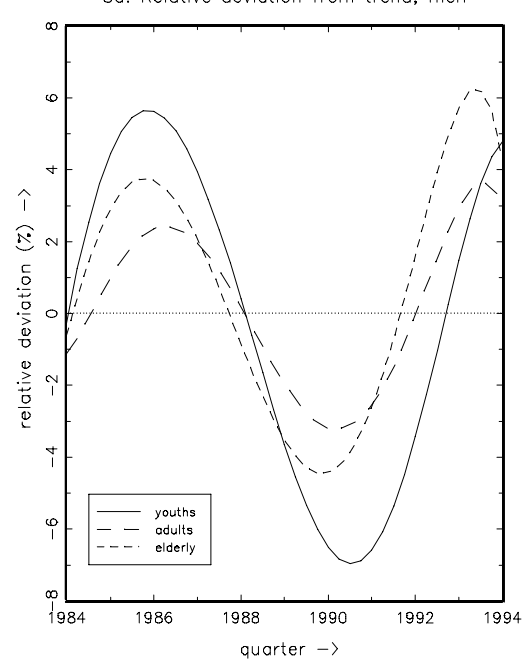


4a. Capacity utilization rate $(\%)$, France

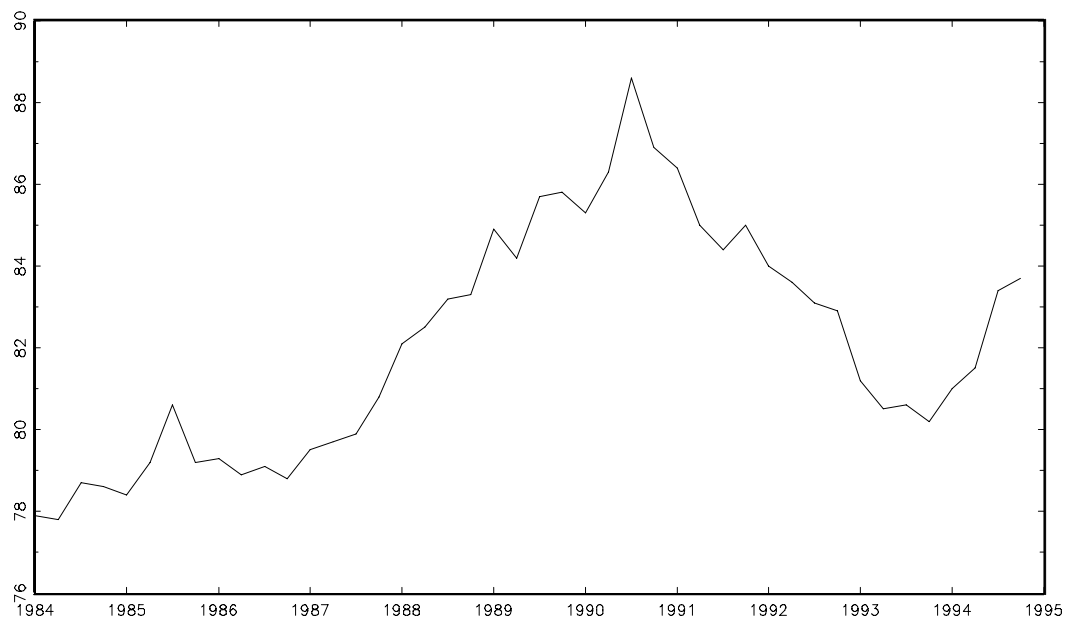

4b. Real GDP growth (\%/year), France

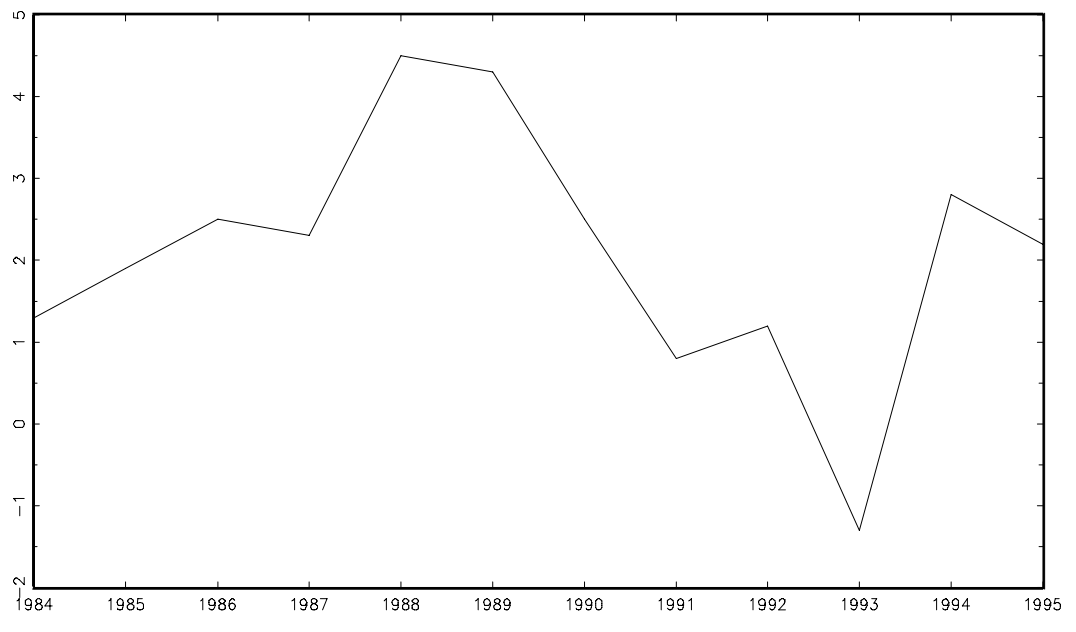


5a. Cycle outflow, women

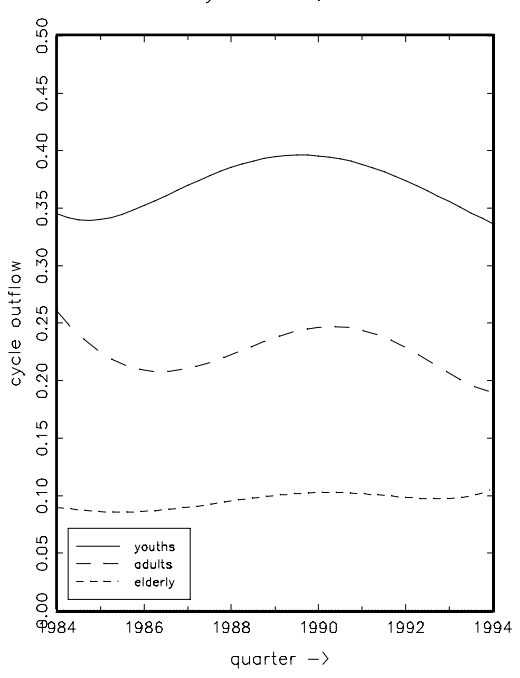

5c. Relative deviation from trend, women

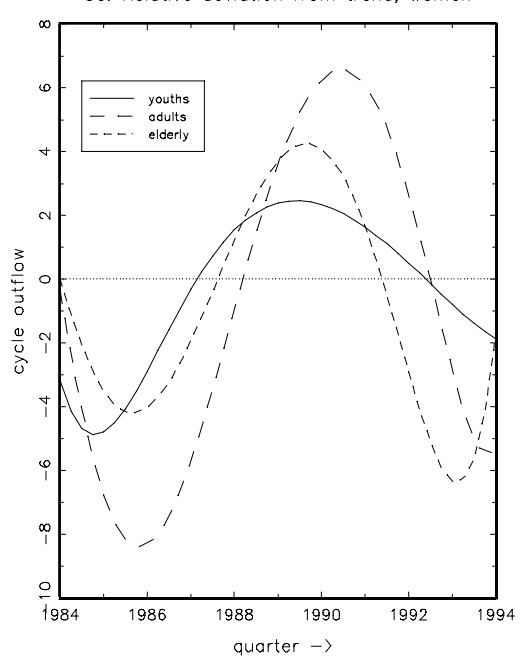

5b. Cycle outflow, men

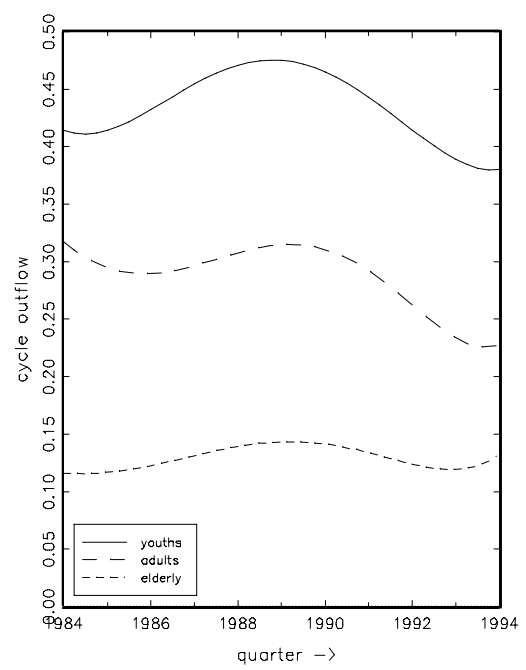

5d. Relative deviation from trend, men

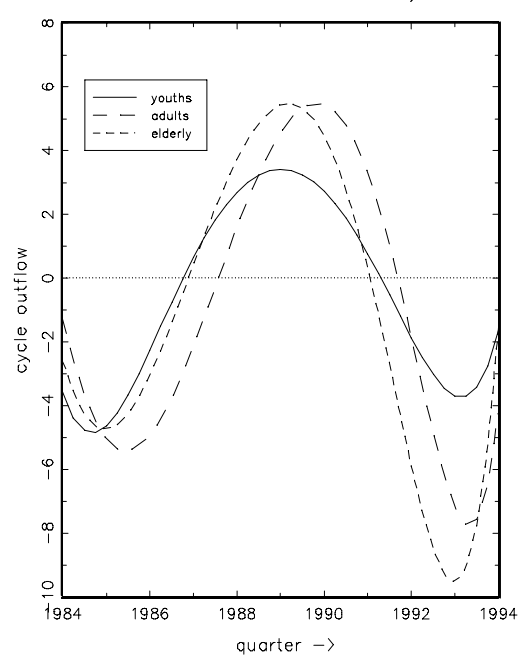


6a. Genuine duration dependence, women

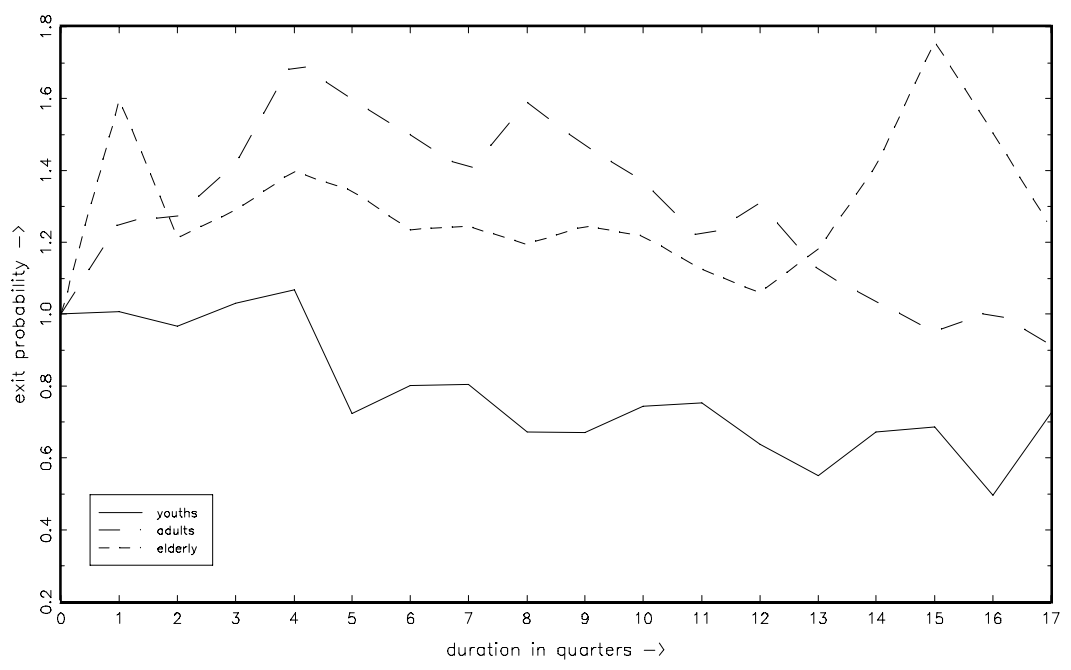

6b. Genuine duration dependence, men

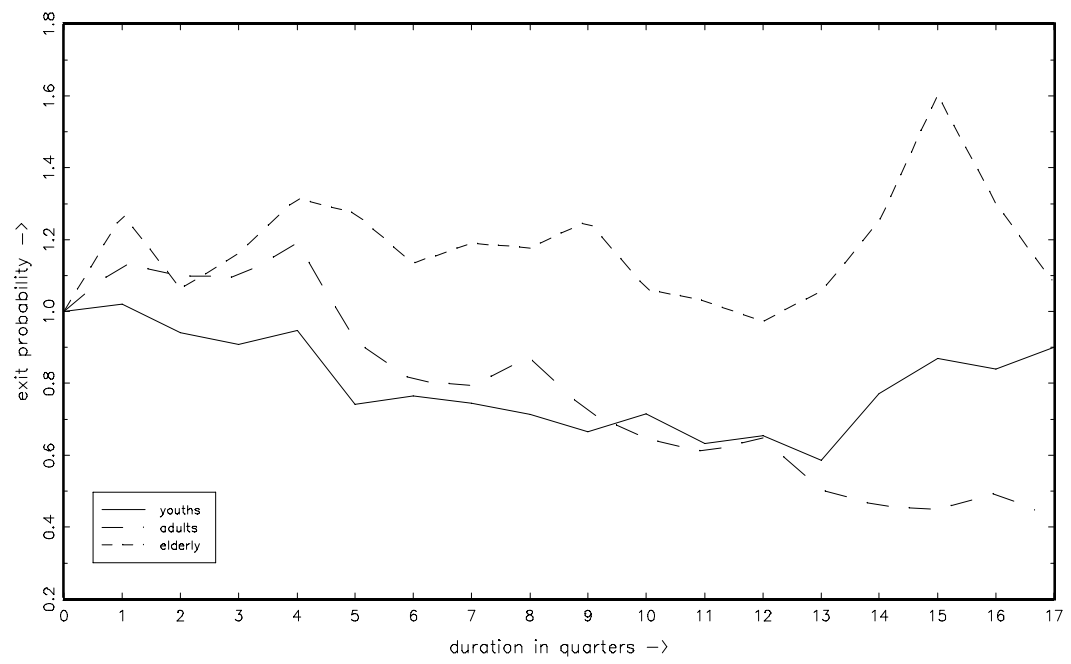

